\title{
Cistitis incrustante tras Mitomicina C
}

\author{
D. Pascual Regueiro, S. García Sánchez*, J. Oliva Encina. M.L. Remón Garijo*, \\ J. Martínez Bengoechea, G. Abril Baquero
}

Servicio de Urología. *Servicio de Anatomía Patológica. Hospital Royo Villanova. Zaragoza.

Actas Urol Esp 2005; 29: 715-718

\section{RESUMEN}

\section{CISTITIS INCRUSTANTE TRAS MITOMICINA C}

La cistitis incrustante o incrustada es un proceso frecuente que se caracteriza por la precipitación de sales en la mucosa vesical. La presencia de orinas alcalinas parece ser un factor fundamental para dicho depósito. Las infecciones urinarias por gérmenes urealíticos también parece ser un factor importante. Presentamos un caso de cistitis incrustante tras el uso de Mitomicina C como quimioterápico intravesical.

Palabras Clave: Cistitis Incrustante. Mitomicina C.

\section{ABSTRACT \\ INCRUSTED CYSTITIS AFTER MITOMICIN-C}

Incrusted cystitis is an infrecuent process characterized by precipitation an incrustation of salts on the vesical mucosa. An alkanine urine is required to this precipitation. The urinary infection with urolithic activity microorganisms can also be a very important factor. We present a case of incrusted cystitis after using Mitomicine as vesical chemoterapy.

Keywords: Incrusted Cystitis. Mitomicin C.

$\mathrm{L}$ a cistitis incrustante o incrustada es una entidad clínico-patológica poco frecuente y que muchas ocasiones puede pasar desapercibida. Como su nombre indica consiste en el depósito a nivel de la mucosa vesical de sales de tipo cálcico (fosfato, carbonato) y amónico magnésica ${ }^{1}$.

Esta precipitación e incrustación de las sales necesita de una serie de factores para que ocurra como son ${ }^{1,2}$

- Orinas alcalinas con pH por encima de 7 .

- Existencia de daño vesical previo.

- Infección urinaria por gérmenes de tipo urealítico.

- Situación de inmunodepresión.

Con respecto al primer punto comentar que las orinas alcalinas son el factor que determina la precipitación de las sales, que por su marcado carácter ácido precipitan en este tipo de medios.
El daño vesical previo no es demostrable siempre según los casos publicados en la literatura, lo que si hay que tener muy en cuenta es la exclusión previa de un proceso maligno vesical como sustrato para el desarrollo de esta precipitación.

Dentro de los gérmenes urealíticos el Corynebacyterium $\mathrm{D} 2^{3,4}$ se destaca como uno de los principales factores patógenos, tratándose de un germen oportunista en muchos casos nosocomial, difícil de detectar y bastante resistente a los antibióticos. No obstante hay casos descritos en los que se ha identificado a E. coli ${ }^{5}$ como agente infectivo, germen por otra parte que no presenta clara actividad urealítica.

Los pacientes inmunodeprimidos y en especial los pacientes transplantados ${ }^{6}$, constituyen el colectivo donde más se ha incrementado el diagnóstico de esta patología. 
A continuación presentamos un caso de cistitis incrustante aparecida en un paciente que siguió ciclos de quimioterapia intravesical con Mitomicina C como tratamiento complementario a su proceso urotelial.

\section{CASO CLÍNICO}

Se trata de un paciente de 47 años de edad que presenta como único antecedente patológico una espondilitis anquilosante con importante merma de la movilidad de la columna sobre todo a nivel cervical.

Desde el punto de vista urológico el primer contacto con el paciente fue por el estudio en agosto de 2001 de una hematuria monosintomática y caprichosa, que tras la realización de un estudio urográfico y ecográfico llevó al diagnóstico de una neoformación de $13 \mathrm{~mm}$ de aspecto papilar en cara lateral izquierda vesical.

Con estos hallazgos se llevó a cabo en noviembre de ese mismo año una resección endoscópica de la citada neoformación, con el diagnóstico anatomopatológico de carcinoma transicional pTa G1.

El paciente continúa con seguimiento ambulatorio con estudios ecográficos y citologías urinarias negativas.

En diciembre de 2003 se realiza una cistoscopia de control, encontrándose el paciente asintomático, con el diagnóstico de recidiva tumoral papilar, de aspecto superficial, en el suelo vesical.

El estudio preoperatorio fue normal, encontrándose en la determinación de orina un sedimento con 35 hematíes/campo, y 100 leucocitos/campo, con un $\mathrm{pH}$ urinario de 7 y un cultivo negativo para gérmenes habituales.

Tres meses después se realiza resección endoscópica de la recidiva, la cual era multifocal, con el diagnóstico de carcinoma transicional pTaG1.

Dada la edad del paciente, la recidiva en menos de dos años, y el carácter multifocal de la misma, se decide, a pesar del bajo grado tumoral, completar el tratamiento con la instilación intravesical de Mitomicina $\mathrm{C}$.

Se programa una instilación semanal durante seis semanas de $40 \mathrm{mg}$ de Mitomicina C, previa instilación de una dosis precoz en las 48 horas siguientes a la cirugía.
La tolerancia a las instilaciones es correcta siendo seguido nuevamente en la consulta.

Encontrándose el paciente asintomático, es visto para revisión en septiembre de 2004 con unas citologías sospechosas pero no determinantes de malignidad y el hallazgo ecográfico de un engrosamiento significativo de la pared vesical anterior, con abscesificación de la misma siendo sugestivo de cistitis. Además, en la zona de la última resección tumoral también existe un área hiperecogénica con relieve de $1,5 \mathrm{~cm}$. de base de implantación, muy sugestiva de recurrencia tumoral.

\section{Imagen 1}

El cultivo de orina fue negativo en esos momentos hallándose un $\mathrm{pH}$ urinario de 8 , y en el sedimento 40 hematíes/campo y 120 leucocitos/campo.

En octubre de 2004 se lleva a cabo una revisión endoscópica bajo anestesia general.

Los hallazgos quirúrgicos son los siguientes:

- Vejiga de capacidad normal

- Zona desflecada con tejido de granulación en la cara anterior vesical habiendo desaparecido la imagen abscesificada de la ecografía

- En el suelo vesical-cara lateral izquierda se aprecia una pseudomembrana de aspecto necrótico que se desprende al roce con el resector.

- Bajo la pseudomembrana aparece una mucosa muy engrosada, desflecada y muy dura al corte con sensación de calcificación en un área de $2 \mathrm{~cm}$.

Se reseca en toda su extensión la lesión descrita con la sospecha de que se tratara de una neoplasia infiltrante con zonas de necrosis por el aspecto endoscópico que presentaba.

El estudio anatomopatológico reveló la existencia de fragmentos de pared vesical con intensa inflamación, áreas de necrosis y depósito de sales inorgánicas entremezcladas con tejido necrótico y fibrina sin evidenciarse tejido tumoral. También se observaban fibras musculares lisas con intensa inflamación y zonas de hemorragia y necrosis, pero sin apreciarse infiltración tumoral (Fig. 1). 

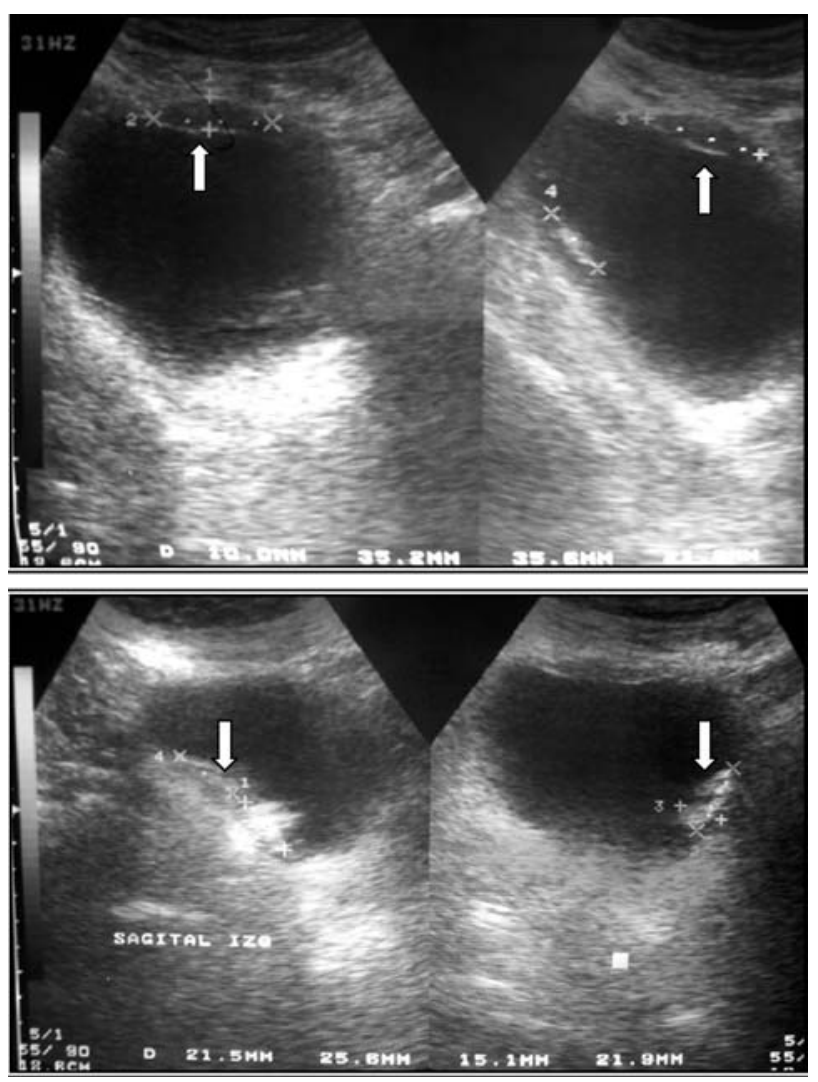

FIGURA 1. Ecografía vesical. En la imagen superior, señalada con la flecha blanca, se aprecia engrosamiento de la cara anterior vesical con aspecto de abscesificación. En la imagen inferior también señalada con flecha blanca se aprecia engrosamiento irregular e hiperecogénico en suelo vesical sin poder descartar neoplasia vesical.

\section{Imagen 2}

El postoperatorio transcurrió sin incidencias, y con el diagnóstico de cistitis incrustante, el paciente fue dado de alta a los tres días de la intervención para su seguimiento periódico en consulta (Fig. 2).

\section{COMENTARIO}

La cistitis incrustante es una inflamación severa de la mucosa vesical que precisa, como se ha detallado en la introducción, de una serie de factores para su desencadenamiento. El factor fundamental de su génesis, el depósito por precipitación de sales, precisa de una situación de alcalinidad urinaria. Como podemos ver en el desarrollo clínico del caso, nuestro paciente presentaba una orina con un $\mathrm{pH}$ de 7 justo antes de la última resección endoscópica, mientras que tras las instilaciones de Mitomicina el $\mathrm{pH}$ se
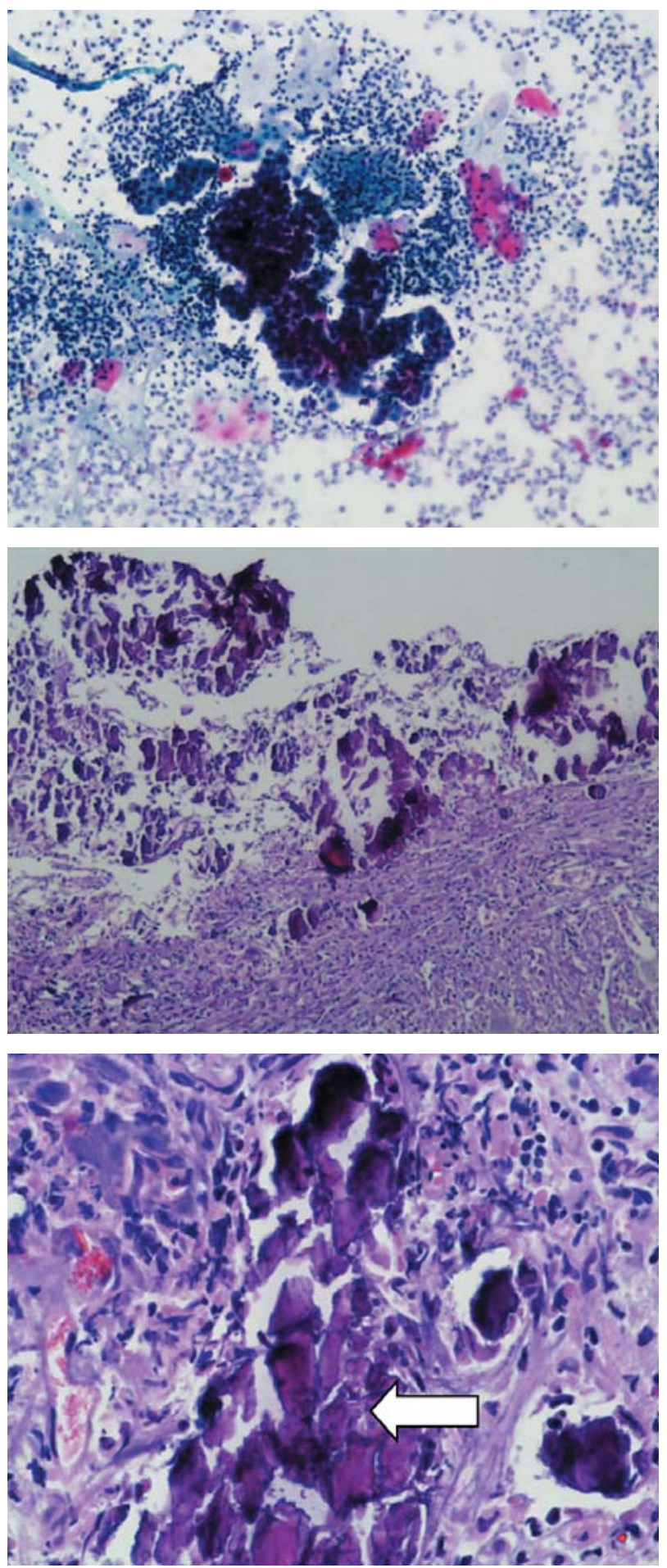

FIGURA 2. Imagen superior: citología urinaria. Fondo con abundantes elementos inflamatorios con agrupaciones papilares atipicas (Papanicolau 10x). En la imagen intermedia: preparación microscópica (H-E 10x). Se aprecia una mucosa vesical con abundante tejido de granulación, amplias áreas de necrosis y depósito de material inorgánico. En la imagen inferior: preparación microscópica (H-E 40x). Detalle a mayor aumento donde se aprecian los depósitos de sales inorgánicas señaladas con la flecha blanca. 
había modificado consiguiendo una mayor alcalinidad ( $\mathrm{pH}$ 8). Tras consultar con el Servicio de Farmacia de nuestro hospital, hemos determinado que la Mitomicina, una vez preparada para su instilación vesical, presenta un $\mathrm{pH}$ final entre 7 y 8 .

En la mayor parte de las series describen un factor bacteriano con propiedades urealíticas como factor precipitante del proceso, y en especial el Corinebacterium D2.

Este germen precisa de determinaciones específicas para su aislamiento, tratándose de un germen oportunista y en la mayor parte de los casos nosocomial.

En nuestro paciente no se ha podido identificar la presencia de gérmenes urinarios en ninguna de las determinaciones. No obstante tenemos un factor importante de contaminación urinaria: el sondaje repetido para las instilaciones de Mitomicina.

El desarrollo de la cistitis incrustante se produce, en la mayor parte de los casos descritos, sobre un fondo lesional vesical. En nuestro caso la lesión está muy clara, por un lado tenemos la herida de la resección endoscópica a la que hay que añadir la inflamación de mucosa que provoca la Mitomicina C y que es inherente a su acción citostática.

$\mathrm{Si}$ aunamos todos los factores podemos determinar que, la instilación de Mitomicina C como agente quimioterápico vesical, tras una resección endoscópica, si bien no puede ser establecida como agente causal directo de la cistitis incrustante sufrida por el paciente, si que es verdad que tanto su acción a nivel de la mucosa vesical, sus características farmacológicas, con un $\mathrm{pH}$ de tendencia alcalina, y la necesidad de un sondaje repetido para su administración, como agente potencialmente contaminante urinario pueden favorecer de forma importante su génesis.

Con respecto al tratamiento de la entidad desarrollada, todos los autores están de acuerdo en que la acidificación urinaria es suficiente para solucionar el proceso. Acción a la que hay que añadir la resección de las placas ya formadas y conseguir la esterilización urinaria ${ }^{1,3,5}$.

En los casos en los que las pruebas de imagen no son llamativas, al contrario del caso descrito, es preciso ante orinas alcalinas con cultivos negativos establecer diagnóstico diferencial con entidades como la TBC urinaria o la bilharziosis ${ }^{1}$.

Es de especial relevancia descartar un proceso neoplásico con áreas necróticas como agente inicial del proceso $^{1}$, lo que nos obligará a un tratamiento y seguimiento del paciente acorde a esa patología.

La no resolución y cronificación del cuadro puede motivar alteraciones urinarias severas como el fallo renal ${ }^{4}$, por afectación asociada del tracto urinario superior, hematuria recurrente $\mathrm{y}$ anemia $^{3}$, disminución de la capacidad vesical por retracción cicatricial e incontinencia. En pacientes trasplantados puede llevar a la pérdida del injerto renal ${ }^{6}$.

\section{REFERENCIAS}

1. Aubert J, Dore B, Touchard G, Loettia G. Alkaline-urine incrusted cistitis. Clinical aspects and treatment. J Urol 1982;88(6):359-63.

2. Rodríguez Tolra J, Serrate R. Cistitis incrustante. Arch Esp Urol 1978 Nov-Dec;31(6):541-550.

3. Ohara H, Yoshimura K, terada N, Ichioka K, Matsui Y, Terai A, Arai Y. Two cases of encrusted cystitis. Hinyokika Kiyo. 2004 Jan;50(1):33-35.

4. Masson JC, Charriere D, Masson J, Varini JP. Corynebacteria D2 and encrusted cistitis with alkaline urine. Prog Urol 1992 Dec;2(6):1012-1017.

5. Romero Pérez P, Amat Cecilia M, Omera Arbash AR, Andrada Becerra E. Cistitis incrustante. Revisión de la literatura y presentación de un caso. Actas Urol Esp 1992; 16(6):496-505.

6. Meria P, Desgrippes a, Arfi C, Le Duc A. Encrusted cistitis and pyelitis. J Urol 1998 Jul;160(1):3-9.

Dr. D. Pascual Regueiro

Avda. Compromiso de Caspe 27-29, $2^{\circ}$ A

50002 Zaragoza

(Trabajo recibido el 4 noviembre de 2005) 